\title{
Arbor
}

\section{Hacia una nueva visión histórica de la Córdoba Islámica}

\section{Antonio Arjona Castro}

Arbor CLXVI, 654 (Junio 2000), 175-190 pp.

En estos años se ha producido, sobre la historia de al Andalus, como apunta María Jesús Viguera, un esfuerzo nuevo de comprensión, que corresponde a una profunda renovación de los métodos de estudio de la historia ${ }^{1}$. Los historiadores seguimos utilizando la documentación conocida, con las ampliaciones mayores o menores incesantemente producidas, con la adecuada combinación de datos procedentes de las fuentes arqueológicas. En Córdoba, la aparición de nuevos fuentes históricas árabes y las continuas excavaciones arqueológicas realizadas desde hace más de quince años, unas publicadas y otras inéditas todavía, justifican esta nueva visión panorámica de Córdoba bajo el Islam.

La entrada de elementos beréberes y árabes portadores del Islam y de formas de vida orientales en la ciudad de la Bética iba a crear las circunstancias propicias para un cambio profundo de la deteriorada Corduba no obstante este cambio, que haría entrar a nuestra ciudad en una de las ciudades de destino en lo universal en expresión de Arnold Toybee, iba a tardar varios siglos. Este cambio se produciría de una manera, paulatina, lenta pero inexorable.

Hay que resaltar el relativo florecimiento que nuestra ciudad tuvo en los siglos III- IV y d. C. como recientes hallazgos arqueológicos han venido a demostrar. La excavación del palacio tardorromano de Cercadilla ha hecho revisar el concepto que se tenía de la Córdoba que encontraron los musulmanes en el siglo VIII. Aunque dicho palatium parece que fue construido a principios del siglo IV, al menos ya desde mediados del s. VI sabemos que parte del edificio se utiliza como centro de culto cristiano y necrópolis por lo menos en el siglo IX y $\mathrm{X}^{2}$. En el siglo V Córdoba fue saqueada por los vándalos, a mediados del 
siglo $\mathrm{V}$ los visigodos expulsan a los saqueadores y se hacen con el control del Sur de Hispania. ${ }^{3}$ En el año 550 Agila ataca Córdoba y profana la tumba de san Acisclo cuya iglesia fue utilizada como establo.

La excavación de una iglesia paleocristiana en la antigua iglesia de Santa Catalina en el Convento de Santa Clara ha precisado que dicha basílica se construyó durante el dominio bizantino de Córdoba entre lo años 554 y 572, construcción relacionada, con el traslado del complejo episcopal desde Cercadilla a San Vicente en sur de la ciudad ${ }^{4}$. Los visigodos después de breve dominio bizantino sobre Córdoba, en el siglo VII, establecen en Córdoba un dux provinciae que se convierte en cabeza de la circunscripción meridional Bética. La iglesia tiene un gran poder en Córdoba y en Hispania, sus obispos tiene activa presencia en los concilios nacionales, este dominio es tal que la mayoría de los vestigios que nos han llegado de la época visigoda guarda relación con la religión cristiana.

Por estas circunstancias cuando los musulmanes conquistan Córdoba se encuentran que los ruinosos edificios romanos y visigodos están siendo utilizados por los cristianos; así ocurre no solo con Cercadilla, donde es posible se ubicara la basílica de San Zoilo ${ }^{5}$, sino también con el monasterio de San Acisclo frente a la Puerta de Hispalis a la vera del camino de Hispalis, cuyos restos fueron excavados en 1950 en la antigua Huerta de Chinales ${ }^{6}$, y con la basilica de los Tres Santos situada en el vicus Turris en el lado oriental de la ciudad $^{7}$. Por la misma causa los musulmanes se encuentran que una figura del Virgen esta colocada en los alto de la Puerta del Puente quizás como fruto del fomento del culto a María durante los siglos VIVII 8 .

Pedro Marfil a raíz de la excavación realizada en la antigua iglesia del Convento de santa Clara en la calle Rey Heredia de Córdoba ha elaborado una hipótesis, bastante sugestiva, sobre el complejo de Cercadilla, el cual considera como resto de un palacio episcopal, aunque construido a imitación de los palacios imperiales, en gran parte arrasado a durante el s.V d.C. y definitivamente a mediados del s.VI d. C. En dicho palacio quedaría en uso, al menos, la basilica de San Félix, posiblemente bajo la advocación del mártir de origen africano con culto en Gerona, del que debían venerarse sus reliquias. Más tarde, en el año 613 d. C. durante el reinado de Sisebuto, esta basílica cambiaría su denominación y advocación por la de San Zoilo, tras el traslado a este lugar de las reliquias de este mártir por el obispo Agapio. Este obispo reformó la basílica, así como construyó un 
monasterio con capacidad para cien monjes. Perduraría esta basílica en época mozárabe, existiendo en esos momentos una escuela de clérigos, a la que perteneció, entre otros, San Eulogio. En ella seguirían custodiándose las reliquias de San Félix y San Zoilo hasta su traslado a Carrión por Fernán Gómez en tomo al año 1070 d.C., pasando a denominarse la iglesia de San Juan de Carrión como de San Zoilo y San Félix.

Un aspecto de interés a tener en cuenta en relación a la identificación de la basílica visigoda de San Zoilo en su perduración en época mozárabe es el hallazgo, relacionado con uno de los enterramientos existentes en el edificio poliabsidado que remata el pórtico al Noreste en el citado yacimiento de Cercadilla, del anillo episcopal del conocido abad Samsón, quien, como nos informan las fuentes literarias, había sido nombrado presbítero en dicha basílica por el obispo Valencio, tras el Concilio de Córdoba del 862 dC.7.9

Para Ángel Ventura Villanueva desde el siglo IV al VI d. C. se produce una retracción del espacio urbano habitado hacia el Sur y del recinto amurallado, junto al Guadalquivir, debida quizás a motivos estratégicos (control del antiguo puente romano), hasta el punto de que es en esta zona donde se ubicará el palacio del gobernador visigodo en el s. VI y la principal basílica cristiana de la ciudad, consagrada a S. Vicente, cuyos restos se localizan bajo la MezquitaCatedral. Los centros del poder político y religioso (inseparables en este período) se trasladan desde el antiguo foro y el palacio de Cercadilla a este sector, manteniéndose allí a lo largo de toda la Edad Media. De la Colonia Patricia, aparte de las ruinas empleadas como canteras, no quedaba ya ni el nombre. ${ }^{10}$

Los musulmanes cuando conquistan Córdoba por pacto tras un breve asalto a sus centros de poder, dejan estos edificios en poder de los cristianos y se establecen no solo en el interior de la medina ${ }^{11}$, convirtiendo las iglesias en mezquitas, como ocurrió a la basílica bizantina de Santa Catalina ${ }^{12}$, sino también en los espacios abiertos que circundan el recinto amurallado de la medina ${ }^{13}$ y en los palacios abandonados por los visigodos que huyeron o murieron en la conquista de la ciudad, que eran propiedad del estado visigodo, como el llamado Palacio de Mugiț, y el Palacio (Balāt) cuyos restos son aprovechados años más tarde para construir la almunia al-Rușāfa por 'Abd alRaḥmān I. Dicho predio y palacio fue adquirido por el primer soberano omeya de al-Andalus al beréber Razīn al-Burnusí. ${ }^{14}$ También ocupan algún antiguo castrum visigodo ${ }^{15}$ como el de Turruñuelos ${ }^{16}$ al Norte de 
Córdoba y que los árabes denominan Qal'at Tudminn ${ }^{17}$, topónimo que quizás oculte el nombre de un noble visigodo llamado Teodomiro18

Esta utilización de palacios o fincas romanas y visigodas era frecuente según se atestigua en la almunia de Quintos llamada después de Ibn 'Abd al'Azīz. ${ }^{19}$

Cuando los musulmanes conquistan Córdoba en el siglo VIII se encuentran pues con un núcleo urbano amurallado que para ellos será la al-madina en los sucesivo: y varios arrabales unos al otro lado del río, Secunda y Tercios y otros a este lado formados todos en torno de antiguos vicos (vici) romanos, monasterios, e iglesias situados a extramuros. En el lado occidental ese sitúan el arrabal de los Pergamineros formado alrededor de la basílica de San Acisclo y en la parte oriental en la calzada romana que salía por la Puerta de Hierro de la almedina hacia el Este, el arrabal de la Torre, donde se ubica la basílica de los Tres Santos (luego iglesia de San Pedro).

El primer crecimiento urbano se realizará durante el siglo VIII, bien hacia la zona septentrional hasta llegar la residencia omeya de al- Rusāfa ${ }^{20}$, bien hacia poniente desde el arrabal de Balāt Mugị̂t (arrabal que aunque fue arrasado en el ,siglo XI volvió a estar habitado en el siglo XII ${ }^{21}$ ) y hacia el Sur entorno al vicus de Secunda. Debido a la sublevación del arrabal en tiempos de al-Hakam I el crecimiento por la otra orilla del río queda detenido ciñéndose el crecimiento principalmente hacia el oeste sobre todo con la fundación de Madinat al-Zahrā’ por 'Abd al-Rahmān III.

Los judíos pos su colaboración especial en la conquista conservaron sus viviendas en el interior de la medina. He podido localizar el barrio de la Judería en la Collación de San Miguel gracias a las noticias que nos aporta Ibn Sahl sobre un pleito por medianería entre la sinagoga judía y la casa de un musulmán, ambas situadas en el interior de la almedina y por los resultados de la excavación de la necrópolis hebrea en los aledaños de la muralla Norte de la almedina. ${ }^{22}$

De cómo fue esta expansión urbana viene como anillo al dedo la descripción que de Córdoba hace un viajero que la visita a mediados del siglo X. Su relato es realista desprovisto del más mínimo halago hacia los omeyas y para Córdoba. Este viajero se llama Ibn Hawqal:

La ciudad más grande de al-Andalus es Córdoba, que no tiene su equivalencia en todo el Magreb, más que en la Alta Mesopotamia, Siria o Egipto, por la cifra de población, la extensión de su superficie, el gran espacio ocupado por los mercados, la limpieza de los lugares, la arquitectura de las mezquitas, el gran número de baños y alhondigas) (al-fundaq). Varios viajeros originarios de esta ciudad, que han 
visitado Bagdad, dicen que ella equivale a uno de los barrios de la ciudad mesopotámica.

Su señor (șạhiba-ha), Abd al-Raḥmān ibn Muḥammad, fundó al Oeste de Córdoba una ciudad que llamó al-Zahrä, sobre el pie de una montaña rocosa intacta, llamada Ŷybal Baltaš. él trazó allí mercados, hizo construir baños, caravasares, alcázares, jardines(al-mutanazah); invitó al pueblo ansioso a vivir allí ordenando promulgar por alAndalus la proclama siguiente: 'Quien quiera construir una casa o elegir un local de habitación próximo al soberano recibirá una prima de 400 dírhemes' Un río de gente se apresuró a edificar; los edificios se hicieron densos y la popularidad de esta ciudad adquirió proporciones, hasta el punto de que las casas formaban una línea continua entre Córdoba y Zahra $\vec{a}^{23}$. El príncipe transportó allí su tesoro, su registro (diwān), la prisión, sus depósitos y sus aprovisionamientos. Todo esto ha sido trasladado y vuelto a traer a Córdoba, porque los Omeyas tuvieron temores infundados sobre esta ciudad, y porque adquirieron mal presagio de los hombres que alli murieron y del pillaje de todos sus aprovisionamientos.

Yo he oído contar a más de un perceptor digno de confianza, funcionarios que conocen a fondo las imposiciones levantadas sobre el país y la renta de 'Abd al-Rahmān ibn Muhammad, que el total de las rentas hasta el año 340 [951) no era inferior a 20 millones de dinares, poco más menos sin contar las mercancías, las joyas labradas, los aparejos de navios, así como las piezas de orfebrería, cuyos príncipes no pueden pasar sin ellas.

Después de la muerte de 'Abd al-Raḥmān ibn Muhammad, en el año 350 (961) la autoridad eligió a su hijo Abū al-'Ași al-Hakam ibn 'Abd al-Rạ̣mān. Este sometió a confiscaciones a los cortesanos de su padre, se apoderó de las riquezas de sus servidores y visires, que habian vivido continuamente a su alrededor. El resultado de esta operación se elevó a 20 millones de dinares, total sobre el que las personas competentes están de acuerdo, facilitando incluso detalles. Esta enorme fortuna no ha sido igualada en su época, en el país del musulmán, más que por las afrentas de Gadanfar Abū Taglib ibn Hasan ibn 'Abd Allāh ben Hamdan este último había operado nuevas tomas sobre las sumas manejadas por los notables en la Alta Mesopotamia y en 'Iráq. El conjunto habia sido superior a la cifra ya nombrada, se dice incluso que se elevaba a 50 millones de dínares. Pero Dios hizo cambiar su fortuna y le hizo perder esta opulencia abandonándole y debilitándole. Es así como el Altísimo tiene la costumbre de actuar en caso de 
beneficios ilícitos, cuando una fortuna es adquirida por la codicia, la injusticia y procedimientos deshonestos.

La mención de la suma que acaba de citar permite recordar la aventura del desgraciado, hijo del desgraciado, cuyas actividades

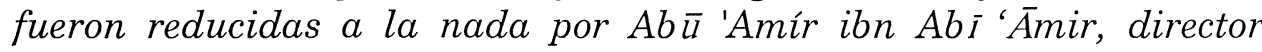
actual de la ceca en al-Andalus. Este gozaba en distribuir dinero y desgraciado el que lo recibía y no le iba bien con el dinero lo volvía a denunciar de no haber hecho fortuna con él.

Después continua: Córdoba es quizás igual a una de las dos mitades de Bagdad, pero no está muy lejos de serio. La medina esta provista de un muro de piedra, de bello emplazamiento y amplias explanadas

Hace mucho tiempo que el soberano de esta ciudad tiene dominio sobre ella y tiene su residencia y alcázar en el interior del recinto amurallado que le rodea..

La mayoría de las puertas de su alcázar alcanzan el interior de la ciudad por varios lados. Dos puertas de la ciudad, están abiertas en la misma muralla de la medina sobre el camino que lleva desde al-Ruṣâfa al río. ${ }^{24}$

Las viviendas Al-Rusâfa son las más alta de sus arrabales y sus construcciones se continúan con el arrabal más bajo de la ciudad. Es una aglomeración que rodea la ciudad por los lados Este, Norte y Oeste. En cuanto la parte del mediodía da sobre el río, a lo largo del cual se desarrolla un camino llamada el arrecife (al-rașif.) y sobre él se encuentran los zocos, tabernas, caravasares, baños y las viviendas de las clases inferiores de la población están en su arrabal. ${ }^{25}$

La mezquita -aljama, que es muy bella y grande, se encuentra en el interior de la medina ; la prisión está situada en su vecindad.

Córdoba está muy separada de las casas de sus arrabales ${ }^{26}$ excepto uno que hay adherido a ella ${ }^{27}$, la medina está situada en el centro rodeada por su muralla, mas de una vez he dado la vuelta a la muralla en una hora; es una muralla de forma circular, muy sólida y de piedra.

Al-Zahr $\vec{a}$ no ha conseguido jamás tener una muralla acabada. Tiene una bonita mezquita- aljama, que posee una gracia propia, pero inferior a la mezquita-aljama de la capital en estructura, capacidad y grandeza.

Córdoba tiene siete puertas de hierro. Es una ciudad considerable y extensa, que presenta un plano elegante.

.. Hasta aquí el relato de este viajero oriental. 
Pero cuando Córdoba musulmana alcanza máximas dimensiones urbanas fue a finales del siglo $\mathrm{X}^{28}$ cuando, durante el califato de Hišām II, el hāŷib lbn Abī' 'Āmir se hizo con todo el poder y mandó construir la ciudad de al-Madīnat al-Zāhira produciéndose el crecimiento urbano hacia la parte oriental. En mi obra Urbanismo de la Córdoba califal ${ }^{29}$ abordé la localización de los restos de al-Madinat al-Zāhira, localización que todavía no se ha visto confirmada por excavaciones arqueológicas..$^{30}$ En esta tarea investigadora de localización tuvo gran importancia los datos que los historiadores dan sobre la almunia de Rabanales que precisamente por ser un nombre no árabe los historiadores hispano-árabes eluden citar su nombre excepto un historiador de origen hispano, decir, Ibn Baškuwāl ${ }^{31}$ que vivió en Córdoba durante el siglo XII. En su obra Sila escribe que dicha almunia o huerta fue un regalo del califa Hišam II al hijo primogénito de Almanzor con motivo de su boda en un acto de generosidad impregnado de debilidad. Tomándolo de un historiador mucho más antiguo, Muḥammad ben Musà ben Fath el conocido por Ibn al-Garrāb, escribe e que era una propiedad de la familia omeya siendo su primer propietario 'Abd al-Raḥmān I y sitúa e ella el famoso episodio de la palmera que otros historiadores señalan ocurrió en la finca de alRuṣafa, y cuenta la anécdota de cómo el primer omeya, sintió nostalgia de su patria Siria, al encontrarse con un palmera solitaria y exclamó con un verso ya famoso:

«Contemplando una graciosa palmera que mora en tierra de alGarb, lejos de sus compañeras, dije: a mí te asemejas en ser aquí forastera y en estar lejos de nuestra tierra y de nuestra familia.

Te has criado en una tierra en la que eres extraña; igual que tú vo me hallo en lugar extraño y alejado. El agua que te riegue sacie tu sed $y$ fortalezca tu vida; iQue las nubes caigan sobre ti convertidas en grata lluvia!"

Este episodio es situado por Ibn 'Iḍārī en la almunia de al-Rușāfa. Se ve que es una leyenda que cada historiador coloca donde le conviene. Esto indica que la almunia de Rabanales era un lugar de recreo (villa) habitada desde época romana no en vano le atraviesa la Vía Augusta y en ella se encontró el primer miliario romano de la calzada que unía Corduba con Roma. Es probable que durante el primer siglo de dominación musulmana de Córdoba fuera propiedad de un noble visigodo y de él pasara al primero de los emires omeyas.

Este cortijo o almunia fue conocida, después de cada pasara a ser propiedad de al-Muzzafar el hijo primogénito de Almanzor, como la Ḥâyibiyya es decir la finca del hạâyib o primer ministro, personaje que 
como describí hace unos años, murió de una angina de pecho en el paraje de Guadalmellato cuando regresaba de una aceifa contra los cristianos $^{32}$. Precisamente cuando la chusma ataca por primera vez alMadīnat al-Zāhira el 15 de Febrero del año 1009 , al ser rechazada la plebe por la guarnición de la ciudad, saquean la citada que dice el cronista árabe estaba la costado de dicha ciudad ${ }^{33}$ y en donde se encontraba la madre de al-Muzzafar la famosa al-Dalfă' (La Chata) que fue tratada con poca delicadeza, pese a ser ella la instigadora de aquella rebelión, que daría al traste con la ciudad de Almanzor. Pero junto a este dato fue indispensable para situar al-Madinat al-Zāhira la localización del puerto fluvial(marsà) de Balliš ${ }^{34}$ donde Ibn Sahl ${ }^{35}$ dice existía una barca para transportaba la gente sobre el río de Córdoba, barca que después de la conquista cristiana es puesta en funcionamiento, al poco tiempo se pierde su uso y de nuevo es restablecida como Barca de las Quemadas ${ }^{36}$ en tiempos de los Reyes Católicos. En el pleito que surge entre la nobleza poseedora del derecho y del lugar del embarcadero, y los usuarios que pedían se restableciese el servicio por ser absolutamente necesario sus funcionamiento, se deduce que hay una antigua vinculación entre la oligarquía terrateniente y el barcaje de las Quemadas con carácter hereditario ,muy anterior a los que hemos dado en llamar nacimiento de la barca en $1490^{37}$. Según la autora de este trabajo, en el pleito se pone de manifiesto, por los enviados al lugar para indagar sobre el asunto, que en dicho lugar hay una camino real que comunicaba la ciudad con el río, en un lugar donde era normal anduviesen barcas y un molinero les dijo, que había oído mencionar a su padre de la existencia de una barca que había caído en desuso y aprovechándose de esto los propietarios de las tierras había construido edificaciones sobre el camino. Viendo que los reyes (RR Católicos) iban a fallar a favor de los peticionarios, los propietarios del terreno se adelantaron y pidieron permiso real para colocar ellos la barca. Los reyes accedieron y dieron permiso a Alfonso de Estepa para que establecieran la barca de las Quemadas. Pero los propietarios de tierras que atravesaba el camino se opusieron a ello por los perjuicios que les ocasionaban en sus propiedades. Un caballero venticuatro del ayuntamiento de Córdoba, llamado Rodrigo de Mesa, el cual se decía propietario de todas tierras que rodeaban el enclave de la barca -situado entre Las Quemadas y Doña Urraca- adujo un testamento acreditativo, según el cual era propietario de la misma barca por sucesión de su padre, en el triple aspecto de propiedad, posesión y señorío. Según este documento su padre la compró aun tal Roy Gonzales Saavedra ${ }^{38}$-Rodrigo de Mesa 
Hacia una nueva visión histórica de la Córdoba Islámica

fue chanciller y alcayde los alcázares de Córdoba, y era señor del Señorío del Chanciller "que está frente a las Quemadas"39. El nombre del Chanciller y el derecho de la barca citada es probable que provengan del chanciller Pedro Martínez chanciller "del Santo Rey Don Fernando" 40 . Se deduce de todo ello que la barca de las Quemadas es heredera de la llamada en época musulmana barca (markab) de Bālliš y ya vimos como decía al-Nuwayri41 que Bālliš era al-Madīnat al.Zāhira.

El topónimo Bāllišs ${ }^{42}$ es transcripción árabe del étimo latino vallis (=valle) una veces da en castellano Velez y otra veces a través del mozárabe evoluciona a una forma apocopada de Val. ${ }^{43}$ Así aparece cerca de las Quemadas el topónimo Fontanar de Valdelecha que creo deriva de Bālliš. De esta población tenemos noticias desde 'Abd alRaḥmān $\mathrm{II}^{44}$, después de la conquista castellana de Córdoba se le cita como una parroquia rural $^{45}$ mal situada por algunos historiadores en Cañete de las Torres cuando en realidad está situada al NW del Cortijo Las Quemadas. ${ }^{46}$ En su origen fue un vicus que jugó un importante papel durante el dominio bizantino de la zona a juzgar por los restos de muralla bizantina que se observan en la zona cercana al embarcadero existente hasta hace poco en el pago de Las Quemadillas, muralla que continua hasta el farallón del Centro de la Asociación Protectora de Subnormales (CAIPO).

Sobre la máximas dimensiones urbanas alcanzadas por Córdoba en el siglo X tenemos el testimonio del escritor del siglo XII alŠaqundi ${ }^{47}$ en la plenitud de su añoranza escribe: "Se dice que estaban tan pobladas las construcciones de Córdoba, al Zahrā’ y al-Zāhira, que se podía caminar por ellas a la luz de las lámparas por espacio de diez millas, sin interrupción alguna." Hoy gracias a la excavaciones arqueológicas realizadas con motivo de la construcción de nuevas urbanizaciones tanto al occidente como al oriente del casco histórico, se ha podido comprobar que estas dimensiones que los historiadores daban para la Córdoba de fines del siglo X no eran exageradas..

Si comparamos la distancia existente entre las ruinas de Madinat al-Zahrā' y las restos de al-Madīinat al-Zāhira en Las Quemadas podemos comprobar que la distancia era aún mayor de diez millas es decir $18 \mathrm{~km}$. en línea recta.

Según al-'Ud́rī (un geógrafo almeriense del siglo XI) ${ }^{48}$ el circuito de Córdoba con todos sus arrabales era de una longitud de 33.000 codos rašašies (lo que equivale a unos $18,150 \mathrm{~m}$.) ${ }^{49}$. Este circuito encerraba una superficie de 2.690 hectáreas. Si suponemos una densidad de 100 
habitantes por hectárea la población de aquella ciudad arrojaría la cifra 270.000 habitantes.

En el Polígono de Poniente, situado al Oeste de la actual Plaza de Toros, donde se ubica Zococordoba, se han excavado unas 35 hectáreas de arrabales con sus viviendas, calles y plazas y si consideramos que en cada vivienda vivían 5 miembros de una familia resulta que nada más que en la zona de las 35 hectáreas del Polígono de Poniente habrían vivido unas 10.000 personas, calculando que hubiera unas 50 viviendas por hectárea, cifra menor que la que da L. Torres Balbás para los recintos amurallados. de Málaga (37,5 hectáreas $=15.000$ habitantes $)^{50}$. Considerando una similar población para cada arrabal de los siete arrabales occidentales que los escritores árabes designan como al-rabaḍ al-Garbī, podrían arrojar una población de cerca de 100.000 habitantes en toda la zona que abarca desde la barriada del Parque Cruz Conde hasta los aledaños de la Huerta del Cañito de María Ruiz (Dār al-Nāūra ). ${ }^{51}$

La parte oriental de Córdoba la que después de amurallada se conocerá como al-madina al-Sarqiyya, es la más poblada y como sus nombres indican, Horno de Burriel, Arrabal de la Torre y Sabular, sus pobladores, al principio de la dominación musulmana, eran cristianos. Otros arables se formarían después en el transcurso de los siglos en torno a cortijos ( almunias),basílicas etc, en el espacio abierto de lo que después de la fitna o guerra civil sería el recinto amurallado de la Ajerquía 52 .

lbn Baškuwāl nos da una relación al parecer topográfica ${ }^{53}$ de los arrabales de Córdoba. La mayoría de los autores hispanoárabes repite que Córdoba llegó a tener en el siglo $\mathrm{X}$ veintiún arrabales, entre los cuales quedaba incluida la medina antigua con dos. ${ }^{54}$ De todos estos al Este había siete: Šabular 'el Arenal', Furn Burrill, 'Horno de Burriel, al-Burŷ 'la Torre', Munyat 'Abd Allāh 'Almunia de 'Abd Alláh', Munyat al-Mugira, 'Almunia de al-Mugira', al-Zahira ${ }^{55}$.

El espacio abierto sobre el que se asentaron dichos arrabales orientales, era atravesado desde época romana por dos calzadas que salían de dos puertas de la medina: la Bāb al-'Abd al-Ŷabbār y la Bāb al-Hadìd. La evolución urbana de este sector oriental de Córdoba fue así : en un primer poblamiento cristiano en los pequeños núcleos de población, vici de época visigoda, Sabular, Horno de Borrel, de la Torre (vico Turris) , almunias que son núcleos de arrabales (rabạ̣) formados a la vera de las dos calzadas romanas que, como hemos dicho, cruzaban el sector confluyendo ambas después en Rabanales para continuar la antigua Vía Augusta o camino de Narbona y Tarragona. 
Desde el siglo IX tenemos constancia ${ }^{56}$ de la instalación en este sector de familias árabes, Banu al-'Abbas, Qurayš, Banu Taqif al-Hurr (Balāt al-Hurr), omeyas como al-Mugira hijo del emir al-Hakam I que dio nombre a un arrabal, omeyas como al-Mutarrif hijo de 'Abd al-Rahmān II que dio nombre al Fahs citado a la salida de la Puerta de ibn 'Abd al-Ŷabbar (espacio abierto llamado en época cristiana Huerta de San Pablo), los Banu Rabi b. Muhammad b. Rabi` encargado de los graneros del Estado que se tuvo su residencia en la maqbura (cementerio) de los Banū al-'Abbās. ${ }^{57}$ Se erigen mezquitas en el siglo IX como la del emir Hišam I cuyo alminar se conserva aun modificado en la Parroquia de Santiago, de la sayyida al-Mustaq (San Lorenzo )y la existente en la almunia de 'Abd Allāh entre otras.

Este sector oriental sigue creciendo hasta el siglo XI donde se ya se han formado distintos como hawma (barrio ) en torno a mezquitas como el de la citada mezquita del emir Hišām I, después en época cristiana collación de Santiago, donde estuvo el primitivo arrabal del Horno de Burriel, otra en torno a la también mezquita de la sayyida Mustaq y el hawmat al-Darb que debería estar cerca de la muralla de la Ajerquía.. Del mismo modo desde el el siglo XI tenemos noticias de la existencia de una zona industrial de Tenerias(al-Dabbigin) y Guarnicionería (Dār al-Sunayf) en el sector S.W del costado ( yānib) oriental de Córdoba. ${ }^{58}$

Es importante señalar que los arrabales orientales de Córdoba son dotados de un recinto amurallado con los Banu Ŷahwar en 1043 y posteriormente cuando pasa a poder de al-Mu'tamid en el año 1069. Después en época almorávide son reforzadas y ampliadas.. Dice Ibn 'Idārī : Se encargó la gente de gente de Córdoba de reparar sus muros ,según la costumbre antigua y se ocupó la gente de cada mezquita de levantar lo que era contiguo. ${ }^{59}$

En época almorávide hay un crecimiento notable de nuevas construcciones sirvan como ejemplo el baño situado frente ala iglesia de San Pedro, y palacios, como el alcázar almorávide excavado en la Parroquia de San Andrés (Palacio de Orive).60 Este crecimiento urbano que prosigue bajo dominio almohade bajo la dirección de Aḥmad ben Basso ${ }^{61}$ al cual viene a Córdoba, como ya vimos en el mes de šawwāl del año 557(septiembre 1161) con el sayj Abu Ya'qūb para reconstruir sus alcázares, edificios y casas y fortificar sus fronteras trayendo consigo desde Sevilla albañiles, arquitectos (alarifes ) y obreros. En efecto en las excavaciones realizadas en la Avenido del Aeropuerto, como antes señalé, se ha podido atestiguar que el arrabal de Balāt Mugīt, que con bastantes probabilidades podemos situar en 
los Llanos de Vistalegre y en el primer tramo de la actual Avenida de Aeropuerto, en época almohade fue habitado de nuevo.

No quiero terminar sin analizar de pasada una cuestión importante la islamización y arabización de la población de Córdoba. La estructura estatal islámica acabó generalizándose en al-Andalus, a través de estos dos grandes procesos, impulsados por el Poder. Se acepta en la actualidad mayoritariamente un proceso de islamización a lo largo del tiempo, que, posiblemente, supuso, durante el siglo $\mathrm{X}$, que el $50 \%$ de los andalusíes fueran musulmanes, según hipótesis, relativamente discutibles, pero orientativas y que armonizan bien con la situación que reflejan los textos, propuestas por R.W. Bulliet ${ }^{62}$, el cual también señala que a principios del XI los musulmanes serían un $80 \%$, y desde el XII al-Andalus contaría con más de un $90 \%$ de musulmanes. En Córdoba estos procesos fueron incluso más rápidos e indicio de ello es la protesta mozárabe del siglo IX. La generalización de la estructura estatal islámica, bien notable desde el $\mathrm{X}$, redujo diferencias entre los elementos de la población, hasta resultar mayoritariamente cohesionados en una entidad andalusí», araboislámica, fuera de la cual la divergencia quedó, en progresiva disminución, representada por algún vestigio clánico árabe y beréber"”, y por los cristianos y judíos de al-Andalus en disminución. ${ }^{63}$

\section{Notas}

1 María Jesús Viguera Molins, La historia medieval en España. Un balance historiográfico (1968-1998). Separata de Al -Andalus: de Omeyas a Almohades. XXV Semana de estudios medievales, 14-18 de Julio de 1998. Estella.

2 R.Hidalgo, "Análisis arquitectónico del complejo monumental de Cercadilla" en la obra Corduba Colonia Patricia, ed. Pilar León, Córdoba, 1993, p.238.

3 J.F. Rodríguez Neila, Historia de Córdoba. Del amanecer prehistórico al ocaso visigodo, Córdoba 1988,p. 525 y ss.

${ }^{4}$ Pedro Marfil Ruiz, "El templo paleocristiano descubierto en la antigua iglesia del convento de Santa Clara en Córdoba“, BRAC n¹31 (1996) pp.197 y s.

$5 \mathrm{Y}$ esta localización la hacemos a consecuencia de la excavación en un solar detrás de la antigua Estación del Ferrocarril en 1991 de un edificio de grandes dimensiones y a todas luces de carácter público que pueden ser los restos del Dar alTiraz que estaba en rabad al-Tiraz donde según el Calendario de Córdoba. En este arrabal estaba San Zolilo. Pedro Marfil Ruiz, "El templo paleocristiano descubierto en la antigua iglesia del convento de Santa Clara en Córdoba“, BRAC n¹31 (1996), p.200.

${ }^{6}$ sobre esta localización Cf. Mi trabajo: "El asedio a la basílica de san Acisclo y Localización del arrabal de los Pergamineros" en revista. Abulcasis n 143 (Sept.1999) pp. 27 con planos etc.

7 Según se deduce del Calendario de Córdoba $(13 / \mathrm{X})$ y de Ibn Sahl, Ahkam alKubrá, Ed. Muhammad Jallaf, Mezquitas y Vieviendas, El Cairo, 1983 p.71. En dicho 


\section{Hacia una nueva visión histórica de la Córdoba Islámica}

lugar había una mezquita y un cementerio situado en la al-sikka al-'uzma o calle mayor de la Ajerquía.

8 F.J. Rodríguez Neila, op.cit. p. 548-549.

9 Pedro Marfil, artic.cit. pp.197 y s.

${ }^{10}$ A.Ventura Villanueva, El Abastecimiento de aguas a la Córdoba romana,II, Ed. Cit. p. 148

11 Como dice al-Maqqari, Analectes, I .166. Mugit después de apoderarse de córdoba encomendó la guarda de la almedina y distribuyó sus soldados en la almedina.

12 P.Marfil, artic. Cit. BRAC n ${ }^{\circ} 131$.

${ }^{13}$ Como 'Āmir descendiente de Abu 'Adà que dio nombre a la Puerta y cementerio occidental de Córdoba y 'Abd al-Ŷabbar ben Jattab b.Marwan b.Nadir en la puerta oriental a mediados del siglo VIII.

${ }^{14}$ Según al-Razi, vid. Ibn Hayyan, Muqtabis edic M.Makki, Beirut, 1973, p. 234 y SS.

15 M. Acien Almansa considera los topónimos Qal'at como la utilización de una fortificación de época visigoda por parte de pobladores árabes en los primeros años de la conquista musulmana de la Península ibérica cf. M.Ảcién, "Poblamiento indígena de al-Andalus e indicios del primer poblamiento andalusí" en Al. 'Qantara XXX (1999) pp. 46 y ss.

16 En Turruñuelos a $4 \mathrm{~km}$ al Este de Madinat al-Zahra', existen dos recintos fortificados de 170/178 m2, soterrados, dotados de una muralla de un notable grosor, según se aprecia por fotografía aérea. En dicho lugar donde han aparecido: un capitel árabe emiral, otro califal con cartela epigráfica que le data en el año 972, y sillares y capiteles visigodos según describió cf. .Rafael Fernández González, "Asentamientos arqueológicos en los ruedos de Córdoba“, en BRAC n83 (1962) pp.211-215. En dicho lugar están los restos de almunia al-Rusāfa, construida sobre los restos de un palacio visigodo cf. mi obra: La almunia de al-Rusafa en el yacimiento arqueológico de Turruñuelos, León 2000 pp.2 y ss ..y mi artículo: A.Arjona y colaboradores "La almunia de al-Rusafa en el yacimiento arqueológico de Turruñuelos" en la revista Abulcasis no 144 (Marzo 2000), pp. 34 y ss.

17 Ajbar Maŷmu'a, p.93. Podría ser Tudmir en vez de Tudmin, Teodomiro, aludiendo a un nombre visigodo.

18 Obsérvese la similitud con del Tudmī n con Tudmīr cf. Al-'Udri, pp.1,3..

19 Cf.el artículo de A.Arjona, Pedro Marfil y Arturo Ramírez laguna "La almunia de Quintos o de Ibn 'Abd al-Aziz" en revista Abulcasis n¹43 (Septiembre 1999) pp. 25 y ss y BRAC $n^{\circ} 137$ en prensa.

20 Dicha almunia la he localizado en el yacimiento arqueológico de Turruñuelos. cf. mi obra:La almunia de al-Rusafa en el yacimiento arqueológico de Turruñuelos, León 2000 pp.2 y ss.y la revista Abulcasis n¹44 (Marzo 2000), pp. 34 y ss Es probable que el arrabal de al-Rusafa y almacabra del mismo nombre, sean los excavados en el Tablero bajo de la Arruzafa por JA Morena y D. Botella aunque no han publicado el informe. Yo he visto amplias superficies tramos de la excavación y pude observar estructuras de viviendas y numerosas tumbas cubiertas de tejas, cf.a.Arjona, Urbanismo de la Córdoba califal, 59-60. Se trata de los cementerios de al-Rusafa y de Furanik cf.R.Pinilla, "Aportaciones ala topografia de Córdoba islámica: almacabras", en Qurtuba n² (1997) 203-205. J.A. Morena López alude indirectamente a esta excavación en su articulo "Nuevas aportaciones sobre Aqua Vetus Augsuta y la necrópolis occidental de colonia patricia Corduba" en Anales de arqueología cordobesa $n^{\circ} 5$ (1994) p.164. Señala que en esta zona norte de Córdoba donde se ubica 
un Centro Comercial encontró dos acueductos, uno tardorromano o bien construido en el siglo VIII, numerosas estructuras hidráulicas, y el cementerio citado.

${ }^{21}$ Parte de este arrabal su cementerio y una mezquita han sido excavados en la zona de Vistalegre y Avenida del Aeropuerto en 1997. Las tumbas estaban cubiertas de tejas como en la almacabra de al.Rusafa. En 1999 se ha excavado en Vistalegre, contigua ala zona anterior, parte de dicho arrabal con restos de un palacio tardorromano edificado con grandes sillares y un alberca romana por las cerámicas y la estratigrafía parece que este arrabal después de se arrasado en el siglo XI fue de nuevo habitado en el XII a juzgar las tumbas halladas en un nivel mas superficial. Todavía no se han publicado los informes de dichas excavaciones.

22 D. Botella, Intervención arqueológica de urgencia en la plaza de Colón, 8 Córdoba, en Anuario Arq. De andalucía, 1992 p.235.

${ }^{23}$ Ibn Hawqal, Kitāb al-Șūrat al-arḍ, ed. J.H. Kramers, pp. 112-114 y trad.María José Romay Suay, Configuración del Mundo,Valencia, 1971 pp.65 y ss.

El arqueólogo Samuel de los Santos halló en 1949 cuando se construía el camino nuevo hacia Almodóvar, llamado de la puesta en riego, restos de un cementerio árabe con numerosas tumbas superpuestas frente al km.2, frente al actual almacenes de Urende y $\mathrm{C}^{\mathrm{a}}$ Sevillana de Electricidad. Y unos $6^{\circ}$ metros más hacía poniente halló restos de un gran edificio con pavimento rojo, árabe, y un grueso murallón de sillares árabes a soga y tizón, de longitud desconocida y dirección NW-SWE cf. Memoria de las Excavaciones del Plan nacional realizadas en Córdoba 1948-1950, Córdoba, 10955, p.41.

24 Arroyo actualmente llamado de Turruñuelos distante del Arroyo del Moro actual, que como es sabido bajaba desde la alomunia de al-Rusafa hacía el río. El arroyo del Moro baja desde el antiguo convento de san Francisco de la Arruzafa y cruzaba por los actuales Jardines de la Agricultura para adosarse como un foso al recinto amurallado de la medina. Como antes he descrito la almunia de al-Rusafa la he localizado en el yacimiento arqueológico de Turruñuelos distante del lugar donde se ubicaban sin fundamento arqueológico los restos de dicha almunia en el lugar actual del Parador de turismo, solar del antiguo Convento de Arruzafa. Cf. mi obra: La almunia de al-Rusafa en el yacimiento arqueológico de Turruñuelos, León 2000 pp. 2 y ss ..y la revista Abulcasis n ${ }^{\circ} 144$ (Marzo 2000), pp. 34 y ss.

${ }^{25} \mathrm{La}$ impresión que tiene Ibn Hawqal es que los arrabales de Córdoba empiezan en la parte alta y sus construcciones se continuaban con los de la parte baja de la urbe. Los arrabales donde dice habitan el pueblo llano ('amma) formaban a estas alturas, año 970, un conglomerado solo interrumpido al sur por el río. En efecto en las excavaciones arqueológicas realizadas entre 1990 y 1997, hemos podido comprobar que las viviendas del arrabal de Ruṣāfa exhumado en el predio llamado del Tablero Bajo se continuaba con las viviendas existentes entre el Parque Figueroa, Huerta de la Reina, y la Barriada de la Paz que a su vez se continuaban con el arrabal excavado en Cercadilla en torno a las basílicas mozárabes (Criptopórtico romano) este arrabal se continuaba con la zona de ciudad Jardín, pues por D.Samuel de los Santos sabemos, se construyó sobre los restos de un extenso arrabal y se continuaba con el excavado en la Zona de Zococórdoba. Del mismo modo por la excavaciones realizadas en el Polígono de Poniente (P1 y P2) y en El Fontanar hemos podido comprobar la continuidad de las construcciones en los arrabales de poniente donde se ha excavado un arrabal y un mezquita de as-Šifa' Por ello los historiadores hablan del arrabal de poniente (rabạ̣ al-garbi). Pero a su vez esas viviendas situadas a poniente de la medina se continuaban por parte próxima al río hacia la zona periférica del alcázar de Córdoba. Esto se ha comprobado por la excavaciones realizadas en numerosos solares 


\section{Hacia una nueva visión histórica de la Córdoba Islámica}

en los Llanos de Vistaalegre y de la calle Pintor Espinosa y parque Cruz Conde. Cf. Mi obra Urbansimo dela Córdoba califal, ed. cit. pp.65 y ss.

26 En efecto los arrabales estaban separados por los espacios abiertos de los cementerios tanto por el Norte como por el Oeste como hemos podido comprobar en recientes excavaciones arqueológicas en la Puerta de Gallegos antigua Bāb al-'Amir alQuraiši y en el Campo de LA Merced (Puerta Osario) zonas desde época romana ocupadas por necrópolis.

27 Se refiere al arrabal llamado de la Ajerquía que desde un principio estaba pegado al muro oriental de la medina.

$28 \mathrm{He}$ estudiado esta expansión y la ubicación de al-Madinat al-Zāhira en Las Quemadas la he estudiado en mi obra Urbanismo de la Córdoba Califal, Córdoba, 1997 pp.141 y ss.

29 Ibid.

30 Los restos de muralla romana hallados en Las Quemadas son restos de las Ilamadas a fines del siglo XII "Torres de al-Zahira "por Ibn Sahib al-Salat. No es de extrañar que Almanzor utilizara sillares romanos restos de la villa romana de Vallis (Balliš) del mismo modo que los mozárabes y musulmanes reutilizaron los sillares romanos del Palatium tardo romano de Cercadilla.

31 Sila edic. Codera, II, p.307 nº443 y edic. El Cairo 1989 al-Ibyāari nº 472 p.328 y ss.

32 Ibn İdāri ,Bayyan III ,p.62 del tetxo árabe ed.Lévi-Provençal, Paris, 1930 y p. 65 de la trad de Felipe Maillo cf. Mi obra Urbanismo de la Córdoba califal pp. 147 y ss.

33 A.Arjona, "Aspectos médicos e históricos de la muerte de al-Muzzafar el sucesor de Almanzor" en revista Corduba, n 6,Vol. II ,1977, fac.3, pp.179-183.

34 Sobre la etimología de este topónimo cf. A.Huici en Enciclopedia del Islam edic.1995 sub voce Balliš.

35 Ibn Sahl, al-Ahkam al-kubrà, edic. de Muhammad Jallaf en Documentos sobre las Ordenanzas del Zoco extraidos de los manuscritos al-ahkam al.-Kubra de Ibn Sahl, El Cairo ,1985 p.96.

${ }^{36}$ María Concepción Laguna Ramírez, El Guadalquivir y Córdoba en el antiguo Régimen, Córdoba, 1997, p.127 y ss.

37 M.C. Laguna Ramírez, op. cit.p.128-129.

38 Archivo Municipal de Córdoba. Barcaje.Duad.2,s/f apud M.C.Laguna op.cit. p.129 nota 39 .

39 Tomas Marques de Castro, Títulos de Castilla y Señorios de Córdoba y su Reino, Córdoba ,1981 p.192.

40 Libro de los Donadios de la Catedral de Córdoba ,Cuadernos de Estudios Medievales, IV-V, Granada (1979).

41 En Nuguairi, Historia de los musulmanes de España y de Africa, texto árabe y trad. Mariano Gaspar y Remiro,Granada, 1917, I, 73 del texto árabe y 65 trad. Cf. mi obra Urbanismo de la Córdob califal, edic c.it pp. 151 y153 notas nº432 y 446.

42 Sobre Bālliš cf. A.Huici en Enc.del Islam $3^{\text {a }}$ ed. ,I,1027.

43 Juan Corominas, Tópica Hespérica, I, 61 F.J.Simonet, Glosario de voces ibéricas...Madrid, 1888, P.561 cf. a.Arjona, Urbanismo de la Córdoba, p.153-4.

44 Ibn İdari, Bayan II edic.paris 1951 p.185.

45 Iluminado Sanz Sancho,Geografía del Obispado de Córdoba en la Baja Edad Media, Madrid, 1995 p. 51,101,127,155,160,162 y 184 .

${ }^{46}$ Cf. mapa Topográfico nacional, Esc. $1 / 50.000$ Hoja nº23 edic.1896. 
47 AL-ŠAQUNDĪ. Elogio al Islam Español. trad. por E. García Gómez de la obra: Risālat fïfadl Al-Andalus, Madrid 1934, p. 104: a 106.

48 AHMAD AL-'UDRĪ, Fragmentos geográficos e históricos, edic. 'Abd al-'Azīz al-Ahwānī, Madrid 1965, p. 122.

49 Según J. Vallve. op. cit.. p. 82.

50 Apud. Basilio Pavón. Ciudades Hispanomusulmanas, Madrid 1992, p. 124.

51 A.Arjona Castro, Arturo Ramírez laguna y Pedro Marfil Ruiz,"Hallados los restos de dar al-Na'ura en el Cortijo del Alcaide y Huerta del Cañito de María Ruiz “en Qurtuba ,2(19997), 333-334 y rev.Abulcasis n¹37(1996) pp. 27 ss.

${ }^{52}$ M.Ocaña, "Notas sobre la Córdoba de Ibn Hazm" en revista al-Mulk n³ (1963 ) p.58.

53 al-Maqqari, Analectes 1, pp. 302 y 303. cf. A. ARJONA, Anales de Córdoba musulmana, ... doc: $\mathrm{N}^{\circ} 271$.

54 Al-Maqqari, Analectes I, 304 que lo tomó de Ibn Baskuwal cf-J-Vallvé, La división territorial de la España musulmana, Madrid,1986 p.252.

${ }^{55}$ Sobre al-Madinat al-Zahira cf-,mi obra Urbanismo de la Córdóba califal pp. 141 al 188.

${ }^{56}$ Ibn Hazm, Ŷanharat al-ansab e Ibn Sahl ,Ahkam al.Kubrá.

57 cf.Ibn Hazm ,Ŷamharat al-ansab, edic.E. Terés ,Al-Andalus XXII(2) (1957) pp. 20,21,28 y 59. E Ibn Sahl. Edic. Muhammad Khlalaf.

${ }^{58}$ Cf-al-'Uḍri, op.cit. p.122 cf. Mi trabajo "Córdoba en el siglo XI según al-'Udri “ ene elBRAC $n^{\circ} 137$ (en prensa).

59 Ibn 'Idari,al-Bayan al-Mugrib, Fragmentos almorávides y almohades, trad. A.Huici, Valencia, 1963 p.172.

60 J.F. Murillo, J.Carrillo ,y S.Carmona "Intervención arqueológica en el palacio de Orive" en Anuario Arqueológico de andalucía, 1992, p. 175.

61 Ibn Sahiib al-Salat, al-Mann bi-l-Imāma, p. 140 del texto árabe, $3^{\mathrm{a}}$ edic del Dr. 'Abd aql-Hadi al-Tazi, Beirut, 1987 y p.48-51 dela trad. de A..Huici.

62 Conversión to Islam in the Medieval Perod, Cambridge MassachussetsLondres, 1979

${ }^{63}$ María J.Viguera, la historia medieval en España. Balance historiográfico, p.92. 